\title{
Evolution Characteristics of Rock Burst Danger Mining in Syncline Environment
}

\author{
Shitan Gu \\ State Key Laboratory of Mining \\ Disaster Prevention and Control Co- \\ founded by Shandong Province and the \\ Ministry of Science and Technology; \\ National Demonstration Center for \\ Experimental Mining Engineering \\ Education Shandong University of \\ Science and Technology \\ Shandong University of Science and \\ Technology \\ Qingdao, China \\ tsgst@163.com \\ Zhimin Xiao \\ College of Civil and Transportation \\ Engineering \\ Hohai University \\ Nanjing, China \\ sdustxiaozhimin@163.com
}

\author{
Bangyou Jiang \\ State Key Laboratory of Mining \\ Disaster Prevention and Control Co- \\ founded by Shandong Province and the \\ Ministry of Science and Technology; \\ National Demonstration Center for \\ Experimental Mining Engineering \\ Education Shandong University of \\ Science and Technology \\ Shandong University of Science and \\ Technology \\ Qingdao, China \\ jiangbangyou123@163.com
}

\author{
Ruifeng Huang \\ State Key Laboratory for \\ Geomechanics and Deep Underground \\ Engineering, School of Mechanics \& \\ Civil Engineering \\ China University of Mining \& \\ Technology(Beijing) \\ Beijing, China \\ huangruifeng310@126.com
}

\begin{abstract}
Based on the theory of Winkler beam on elastic foundation, mechanical model of syncline genesis was established and deflections, bending moment and strain energy were deduced. Meanwhile, stress and energy conditions mining in syncline structure were analyzed from the point of formation mechanism of syncline structure using ground pressure theory and UDEC numerical simulation method. The results show that the formation of syncline is influenced by multiple factors. The larger the buried depth of coal seam, bulk density of overlying strata, characteristic coefficient and tectonic stress, the smaller foundation coefficient, and the easier syncline structure can be formed. Meanwhile, the closer the distance of working face to synclinal axis, the larger the ratio between shear and vertical stress and the surplus energy at the peak of abutment pressure in front of coal wall, and the greater the occurrence possibility of rock burst.
\end{abstract}

Keywords-syncline structure, deflection, energy distribution, rock burst danger, shear instability

\section{INTRODUCTION}

With the depth and intensity of coal mining increasing in China, rock burst has been one of major mine disasters, especially in deep mining[1-2]. As a special form of strata behaviors, rock burst was a process of sudden release of elastic strain energy accumulated in coal and rock mass, and it had obvious dynamic characteristics compared with general underground pressure phenomenon[3]. Coal and rock mass in the geological structure zone had a higher rock stress, and superposition with abutment pressure made it be in a state of high static load and accumulate large amounts of elastic strain energy in the mining process[4]. During the process of mining, rock burst was easily induced by the interaction between dynamic load produced by rotational movement of the roof and coal and rock mass in high static load state.
There were lots of studies on rock burst induced by faults under the influence of mining, such as Zhu et al. [5] analyzed the stress state and mechanical response of fault rock system based on voussoir beam theory, and revealed the rock burst disaster mechanism induced by fault slip; Li et al. [6] researched on the rules of rock burst caused by faults used by mechanical analysis and numerical simulation, and found that the risk of fault-slip rock burst is higher when the longwall face advances from footwall to the fault itself than when the face advances from hanging wall to the fault; Sainoki and Mitri [7, 8] established the dynamic modeling of fault slip and studied the dynamic behavior of mininginduced fault slip through numerical simulation; Li et al. [9] establishing mechanical model of fault locking and unlocking slip and putting forward a concept of rock burst of coal pillar type in fault zone; Cai [10] studying on the principle of superposition of static and dynamic load inducing rock burst of fault; Liu et al. [11] established a mechanical model of fault slip and proposed the pattern recognition of signal for fault-slip rock burst. In summary, regarding aspects of fault type rock burst, a great deal of effective research has been done on the influencing factors and mechanism of rock burst. However, researches about rock burst characteristics and mechanism induced by mining in the conditions of folded structure are very scarce. Guo et al. [12] researched the progressive mitigation method of rock bursts under complicated geological conditions based on the Jingxi Coalfield which is called "China's Geological Encyclopedia"; Zhang et al. [13] found that the core of a fold syncline had more intense tectonics than other positions, causing the concentration of local in situ stress, from four extremely intense rock bursts; Wang[14] inverted the process of formation and stress distribution of the fold used numerical simulation method, and investigated the mechanism and control of rock burst]. Jiang et al.[15] using the micro seismic monitoring method studied classification 
and early warning method of tectonic-controlled rock burst, which was divided into two types: stress-increasing type and stress-decreasing type. In general, fold structure can be divided into anticline structure and syncline structure. The characteristics and mechanism of rock burst under different fold structure types is quite different. Regarding aspects of anticline structure, $\mathrm{Gu}$ et al. [16] studied the formation mechanism of an anticline structure and its disaster mechanism of rock burst by theoretical analysis and UDEC numerical simulation. Regarding aspects of anticline structure, the related literature is very rare.

Influence factors were extremely complex, which induced rock burst near the syncline structure where harm caused was extremely serious. Research showed that with the working face crossing fold area, most of strong earthquake occurred in synclinal shaft in which impact dynamic disaster occurring was higher than other positions[17]. At present, tectonic stress of the synclinal shaft, energy evolution process and control action of rock burst were not studied sufficiently[18] under the mining influence. In view of above situations, methods of theoretical analysis and numerical simulation were used to study mechanism of the synclinal causes, law of energy evolution and synclinal axis stress under the mining influence. And disaster mechanism of rock burst induced in the synclinal axis was explored.

\section{THEORETICAL SOLUTIONS OF FORMATION OF THE SYNCLINE IN IDEAL CONDITIONS}

\section{A. Theoretical solutions of formation of the syncline}

Layered medium was basic mechanical characteristics of coal and rock strata. Weight of overlying strata was equivalent to role of uniformly distributed loads, and the lower part was the floor with common deformation. Compared with the overlying strata, thickness of coal seam was very small. Therefore, coal seam can be equivalent to the infinite long beam subjected to uniformly distributed load in elastic foundation. By literature [16], force couple was the main factor in its development during the formation of fold. Therefore synclinal tectonic stress could be equivalent to a pair of concentrated couples. Mechanical schematic diagram of fold causes was shown in Fig. 1, where the left side of the $\mathrm{w}$ axes formed syncline, and the right side formed anticline. Because of studying mechanism of the synclinal causes, the left part was separated out and shown in Fig. 2.

In this paper, the Winkler elastic foundation model was used to analyze mechanism of the synclinal causes and width of the beam was set for 1 . The general solution of synclinal deflection equation can be expressed in (1) [19]:

$$
\begin{aligned}
w(x)= & e^{\alpha x}(A \cos \alpha x+B \sin \alpha x)+ \\
& e^{-\alpha x}(C \cos \alpha x+\mathrm{D} \sin \alpha x)+w_{0}(x)
\end{aligned}
$$

Where $\alpha$ was the characteristic coefficient and $\alpha^{4}=k / 4 E I$, $k$ was the foundation coefficient, and $\omega_{0}(x)$ was a special solution of the equation.

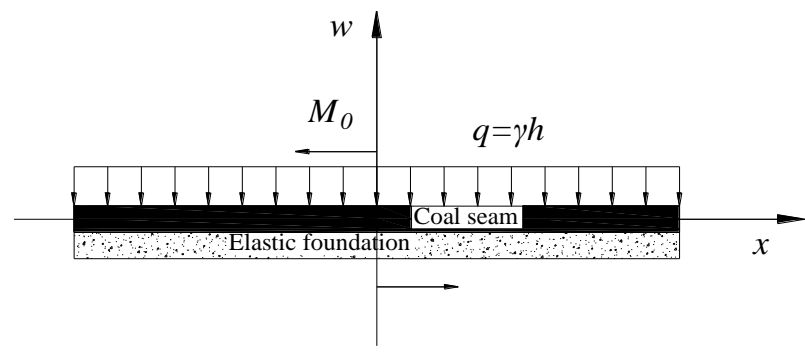

Fig. 1. Schematic diagram of fold

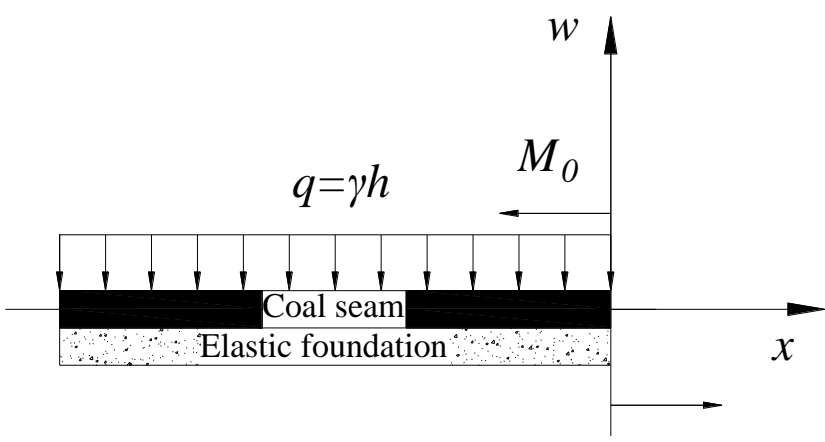

Fig. 2. Schematic diagram of synclinal structure

When the infinite beam was only subjected to uniform load, the static equilibrium relationship can be known [20]:

$$
p=q=\gamma h=K w_{0}(x)
$$

Thus, the $\omega_{0}(x)$, a specific solution, can be expressed as $\gamma h / k$. And the deflection equation of the infinite long beam only subjected to uniform loads can be shown in (3):

$$
\begin{aligned}
w(x)= & e^{\alpha x}\left(A_{1} \cos \alpha x+B_{1} \sin \alpha x\right)+ \\
& e^{-\alpha x}\left(C_{1} \cos \alpha x+D_{1} \sin \alpha x\right)+\frac{\gamma h}{K}
\end{aligned}
$$

The natural boundary conditions and continuous deformation conditions of the beam were known in Fig. 2:

$$
\left.\omega_{1}\right|_{x \rightarrow-\infty}=\frac{\gamma h}{K},\left.\omega_{1}\right|_{x=0}=\frac{\gamma h}{K},\left.\frac{d \omega_{1}}{d x}\right|_{x=0}=0
$$

It can be obtained separately solutions: $\mathrm{A} 1=\mathrm{B} 1=0, \mathrm{C} 1$ $=\mathrm{D} 1=0$, which substituted into (3) can be obtained (4)

$$
\omega_{1}=\frac{\gamma h}{K}
$$

Seen by material mechanics: $d \omega^{2} / d x^{2}=M / E I$, therefore, the second order derivative of (4) can be obtained:

$$
M_{1}=0
$$

When the infinite beam was only subjected to the action of a concentrated couple, the general solution can be expressed in (6) 


$$
\begin{gathered}
\omega_{2}(x)=e^{\alpha x}\left(A_{2} \cos \alpha x+B_{2} \sin \alpha x\right)+ \\
e^{-\alpha x}\left(C_{2} \cos \alpha x+D_{2} \sin \alpha x\right)
\end{gathered}
$$

The natural boundary conditions and continuous conditions of the beam were known in Fig. 2:

$$
\left.\omega_{2}\right|_{x \rightarrow-\infty}=0,\left.\omega_{2}\right|_{x=0}=0,\left.M\right|_{x=0}=\frac{M_{0}}{2}
$$

It can be obtained separately Solutions:

$$
A_{2}=0, B_{2}=\frac{M_{0} \alpha^{2}}{K}, C_{2}=D_{2}=0
$$

Which Substituted into (6) can be obtained:

$$
\omega_{2}(x)=\frac{M_{0} \alpha^{2}}{K} e^{\alpha x} \sin \alpha x
$$

Moment equation of the infinite beam only subjected to concentrated couple can be obtained by the two order derivative of the (7):

$$
M_{2}(x)=\frac{M_{0}}{2} e^{\alpha x} \cos \alpha x
$$

Using the superposition principle, the theoretical solution of the mechanical model shown in Fig. 2 was obtained by (4), (5), (7) and (8):

$$
\begin{gathered}
\omega(x)=\frac{M_{0} \alpha^{2}}{K} e^{\alpha x} \sin \alpha x+\frac{\gamma h}{K} \\
M(x)=\frac{M_{0}}{2} e^{\alpha x} \cos \alpha x
\end{gathered}
$$

By the material mechanics, the strain energy of a micro section of a beam can be expressed in (11):

$$
d V_{\varepsilon}=\frac{M^{2}(x)}{2 E I} d x
$$

By (10), (11), the equation of strain energy of a microsegment syncline can be shown in (12):

$$
\omega(x)=\frac{M_{0} \alpha^{2}}{K} e^{\alpha x} \sin \alpha x+\frac{\gamma h}{K}
$$

By (9), in the case of sectional flexural stiffness EI being certain, when depth coal buried was deeper and average bulk density of the overlying strata was greater, meanwhile, the foundation coefficient was smaller, the sectional flexural stiffness $E I$ was easily overcome by $M_{0}$. And the syncline structure was easily formed. If not, coal seam would continue to keep level state, and the synclinal structure would not appear.

By (11), (12), the strain energy was closely related to the stress environment and the properties of the elastic foundation beam within micro segment $d x$. When tectonic couple was larger and flexural stiffness was smaller, the strain energy at micro segment $d x$ was larger. With the energy released instantaneously, rock burst was induced easily.

\section{B. Calculation analysis of Synclinal deflection}

The thickness of coal seam was $6 \mathrm{~m}$, and the elastic modulus of the coal seam was $E=4.43 \mathrm{GPa}$, then the $E I=7.974 \times 10^{10} \mathrm{~N} \cdot \mathrm{m}$. Foundation coefficient $K$ was taken 4 $\mathrm{GPa}, 8 \mathrm{GPa}$ and $12 \mathrm{GPa}$ respectively; Rock bulk density $\gamma=$ $25 \mathrm{KN} / \mathrm{m}^{3}$, buried deep $h=800 \mathrm{~m}$, tectonic stress concentration coefficient was taken 1,2 and 3 respectively, and the corresponding couple $M_{0}$ were $2.0 \times 10^{8} \mathrm{~N} \cdot \mathrm{m}, 4.0 \times 10^{8}$ $\mathrm{N} \cdot \mathrm{m}$ and $6.0 \times 10^{8} \mathrm{~N} \cdot \mathrm{m}$. According to above values and (9), the effects of synclinal deflection were studied due to $M_{0}$ and $K$ varies.

a)Synclinal deflection varies under the influence of different tectonic couples

Deflection curves of the syncline under different tectonic couples were showed in Fig. 3, with foundation coefficient $K$ $=4 \mathrm{GPa}$, buried depth $h=800 \mathrm{~m}$.

From Fig. 3, syncline structure was extremely sensitive to varies of tectonic couple. In the same situation of lithology and buried depth, with the increase of tectonic couple value, level of depression of syncline increased. The size of tectonic stress was directly reflected by the level of depression of syncline and size of the wing angle. When tectonic stress increased, both of them increased, while tectonic stress decreased, both of them decreased.

b)Syncline deflection varies under the influence of different foundation coefficients

The tectonic couple $M_{0}=6.0 \times 10^{8} \mathrm{~N} \cdot \mathrm{m}$, buried depth $h=800 \mathrm{~m}$, deflection curves of the syncline under different foundation stiffnesses were shown in Fig. 4.

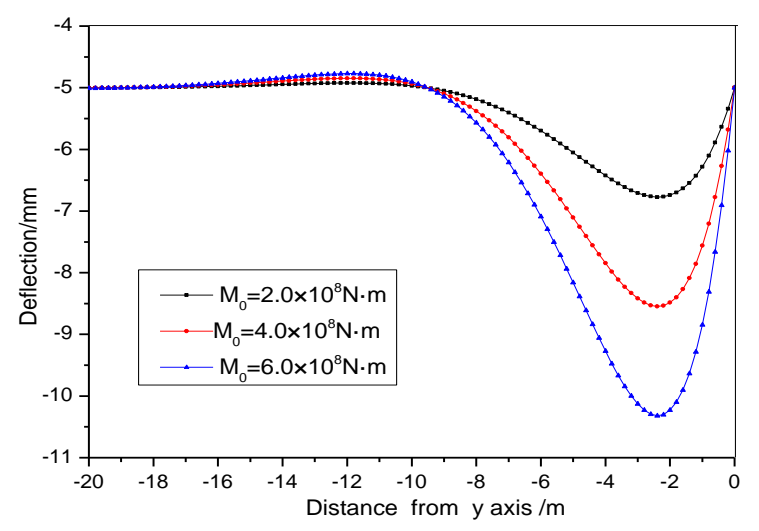

Fig.3. Deflection curves of syncline under different tectonic couples 


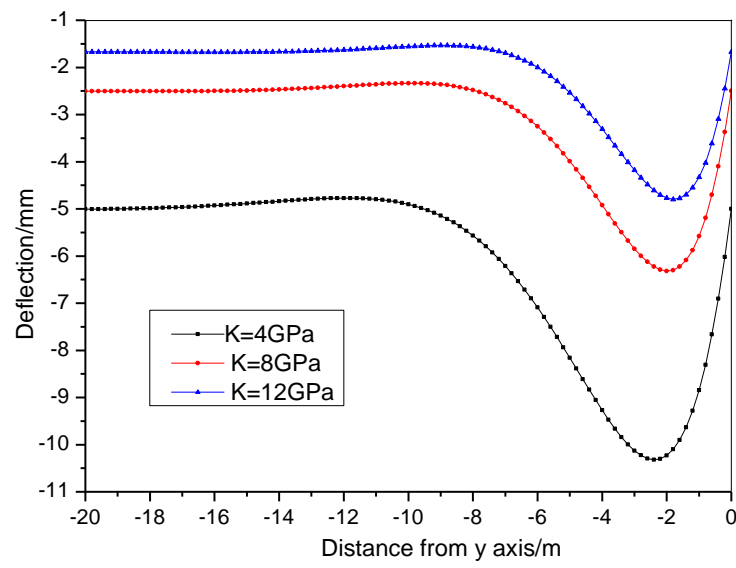

Fig.4. Deflection curves of syncline under different foundation stiffnesses

From Fig. 4, in the same situation of buried depth and tectonic couple, with the increase of the foundation stiffness, and synclinal deflection reduced, namely the level of syncline depression was lower. With increase of the foundation stiffness, syncline was difficult to form. In the mining and excavating process, when there was a thick key layer in the syncline upper or lower sections, these areas should be highly valued which were not only a high tectonic stress, but also a confined water and gas anomaly zone. In the mining and excavating process, exploration was strengthened and prevention and control of rock burst, gas and water-related disasters were combined. Influenced by mining, high tectonic stress and mining stress were superimposed, which may induce rock burst, water inrush and gas outburst.

\section{NUMERICAL MODEL OF SYNCLINE STRUCTURE INDUCING RISK OF BURST}

For the syncline structure's form and rock burst-related features, UDEC model was used to simulate interaction of mining and high tectonic stress in synclinal axis section in this article. Model length $\times$ height was equal to $300 \times 180 \mathrm{~m}$, and coal seam thickness, immediate roof, direct bottom, main roof and basic bottom were taken separately $6 \mathrm{~m}, 3 \mathrm{~m}$, $5 \mathrm{~m}, 15 \mathrm{~m}$ and $15 \mathrm{~m}$.

The model was hinged at the left and right level boundary, and the lower boundary was constrained in the vertical direction. The upper boundary was applied to the vertical equivalent load $(P=\gamma h)$ to simulate weight of the overlying strata. $\gamma$, the average bulk density of the overlying strata on the model, was $25 \mathrm{kN} / \mathrm{m}^{3}$ and $\mathrm{h}$, the distance between the upper surface of the model and earth's surface, was $800 \mathrm{~m}$. So the equivalent load was $20 \mathrm{MPa}$ on the model. Due to structural units of the level causes, the maximum principal stress in horizontal direction was 3 5 times higher than that of vertical stress, the model was applied to the initial horizontal stress $60 \mathrm{MPa}$ in the shaft portion. The model was shown in Fig. 5, and the detailed mechanical parameters of rock mass were shown in Table I .

TABLE I. CALCULATION PARAMETERS OF ROCK MECHANICS

\begin{tabular}{|c|c|c|c|c|c|c|}
\hline Lithology & $\begin{array}{c}\text { Bulk } \\
\text { modulus } \\
/ \mathrm{GPa}\end{array}$ & $\begin{array}{c}\text { Shear } \\
\text { modulus } \\
/ \mathrm{GPa}\end{array}$ & $\begin{array}{c}\text { Internal } \\
\text { friction angle } \\
/\left(^{\circ}\right)\end{array}$ & $\begin{array}{c}\text { Cohesion } \\
/ \mathrm{MPa}\end{array}$ & $\begin{array}{c}\text { Tensile } \\
\text { strength } \\
/ \mathrm{MPa}\end{array}$ & $\begin{array}{c}\text { Density } \\
/(\mathrm{g} \cdot \mathrm{cm}-3)\end{array}$ \\
\hline Gritstone & 18 & 10.5 & 34 & 8.9 & 1.8 & 2.65 \\
\hline Sandstone & 33.1 & 24.81 & 37 & 4.3 & 1.66 & 2.6 \\
\hline Gritstone & 18 & 10.5 & 34 & 8.9 & 1.8 & 2.65 \\
\hline Fine sandstone & 23 & 12 & 30 & 7.5 & 1.2 & 2.7 \\
\hline Siltstone & 15.6 & 10.8 & 30 & 7.2 & 5.0 & 2.6 \\
\hline Gritstone & 18 & 10.5 & 34 & 8.9 & 1.8 & 2.65 \\
\hline Coal seam & 3.13 & 1.28 & 28 & 3.5 & 0.9 & 1.48 \\
\hline Sandstone & 33.1 & 24.81 & 37 & 4.3 & 1.66 & 2.6 \\
\hline Sandstone & 23 & 12 & 30 & 7.5 & 1.2 & 2.7 \\
\hline Sandstone & 33.1 & 24.81 & 37 & 4.3 & 1.66 & 2.6 \\
\hline Medium sandstone & 21 & 12 & 40 & 7.3 & 5.9 & 2.5 \\
\hline Fine sandstone & 23 & 12 & 30 & 7.5 & 1.2 & 2.7 \\
\hline
\end{tabular}

\section{NUMERICAL ANALYSIS OF SYNCLINE MINING ENVIRONMENT}

\section{A. Abutment pressure of working face under different advancing steps}

Abutment pressure of $60 \mathrm{~m}$ range in front of coal wall was monitored by numerical simulation. Under different advancing distances, varies of abutment pressure in front of coal wall were shown in Fig. 6.

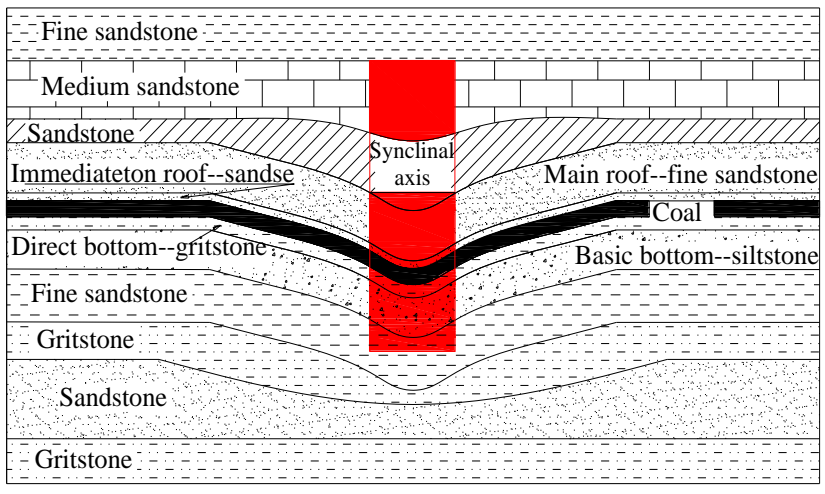

Fig.5. Numerical model of syncline structure 

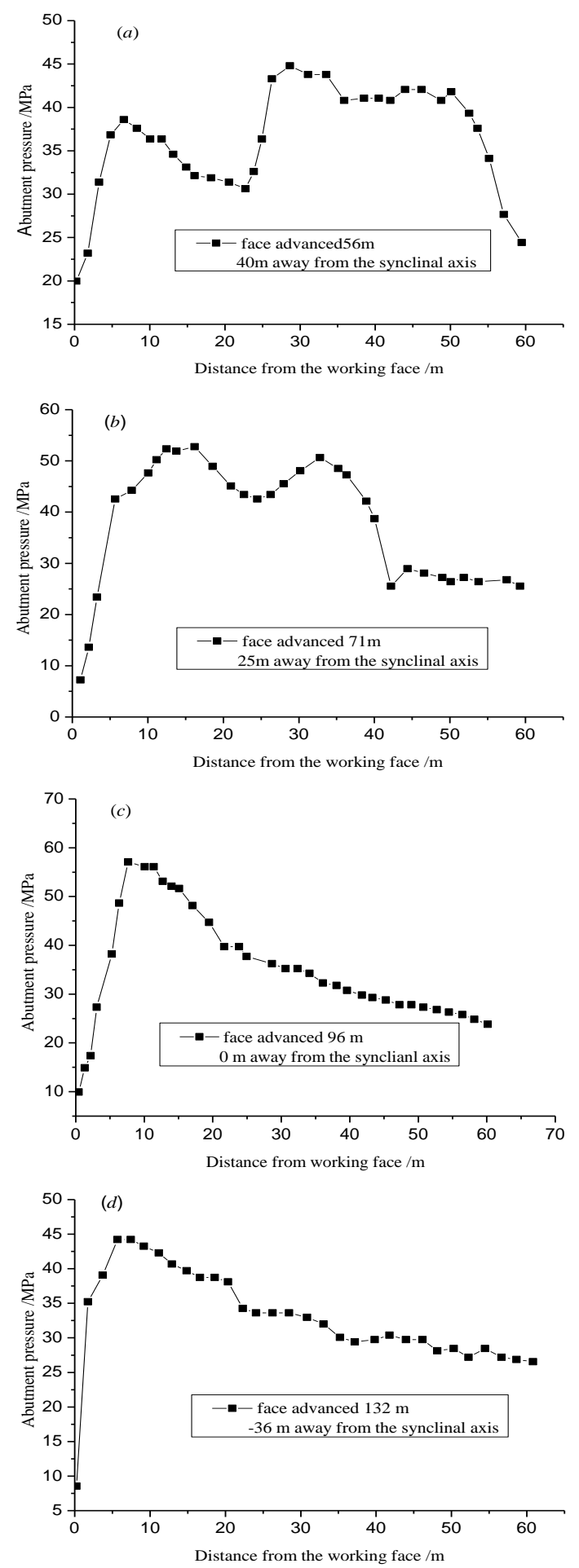

Fig.6. Curves of abutment pressure in front of coal wall under different advance distances

Fig. 6 was shown that: 1) in the Fig. 6(a)-(c), along with working face advancing, abutment pressure in front of the coal wall increased continuously. When working face advancing to the synclinal axis, abutment pressure reached the maximum value $57 \mathrm{MPa}$ and risk of burst was greatly enhanced. When working face passed synclinal axis, abutment pressure peak began to decrease and risk of burst was weakened. 2) The influence range of abutment pressure was about $20 \mathrm{~m}$. Along with working face advancing forward, abutment pressure interacted with high rock stress in the synclinal axis and the influence range of abutment pressure was expanded continuously. And interaction area was serious region of risk of burst. When working face passed synclinal axis, the influence range was weakened slightly. 3) With working face advancing, abutment pressure in front of working face and high tectonic stress of syncline had a "connection - superimposed - Separation" relationship. Fig. 6(a) was shown that abutment pressure in front of working face began to be connected with high tectonic stress of syncline. In Fig. 6(b)-(c), they were superimposed on each other. When working face advanced to the position of Fig. 6(d), superimposed pressure was separated and abutment pressure was slightly reduced. The connecting zone and superimposed area were serious areas where rock burst was emerged in the working face and roadway.

\section{B. Analysis of shear instability in front of the coal wall under different advancing steps}

\section{a) Shear instability criterion of coal and rock mass}

The natural rock mass was cut into block body arranged according to certain rules by the joints, cracks, and so on. The structural plane was closed by the high tectonic stress and the high elastic strain energy was stored in the closed structural planes and its surroundings. Affected by mining, once rock mass had a shear failure along some structural planes, the elastic strain energy stored in the structural plane and adjacent rock masses may be released instantaneously from the mining influence space, which might induce rock burst.

It was assumed that stress state of rock mass was shown in Fig. 7, which $\sigma_{1}$ represented the maximum principal stress, $\sigma_{3}$ was the minimum principal stress, $\sigma_{\alpha}$ was the normal stress of the structural plane, $\tau_{\alpha}$ was the shear stress of the structural plane, $R$ was resultant force, and $\alpha$ was the angle between $\sigma_{\alpha}$ and $R$. The relationship between normal stress and shear stress acting on the structural plane can be expressed by the following formula:

$$
\tau=\sigma f=\sigma \tan \varphi
$$

Among them, $\varphi$ was the friction angle of contact surface of rock mass.

Thus, the relationship between $\alpha$ and $\varphi$ can be used to determine whether rock mass had a sliding instability, and the criterion was as follows:

$$
\left.\begin{array}{l}
\text { Stability: } \alpha<\varphi \\
\text { Limit }: \alpha=\varphi \\
\text { Destruction }: \alpha>\varphi
\end{array}\right\}
$$

Therefore, the closer $\alpha$ was to $\varphi$, the more unstable rock mass was, that was, $\tan \alpha$ was closer to $\tan \varphi$, rock mass was not stable.

$$
\tan \alpha=\frac{\tau_{\alpha}}{\sigma_{\alpha}}
$$

For a specific rock mass, the larger tan $\alpha$ was, the more unstable structure was, the bigger shear instability' possibility 
was. The position of abutment pressure peak was a serious area of risk of burst, and the risk of burst under the working face advancing different steps was expressed by ratio of shear to vertical stress based on the position of abutment pressure peak in the front of the coal wall.

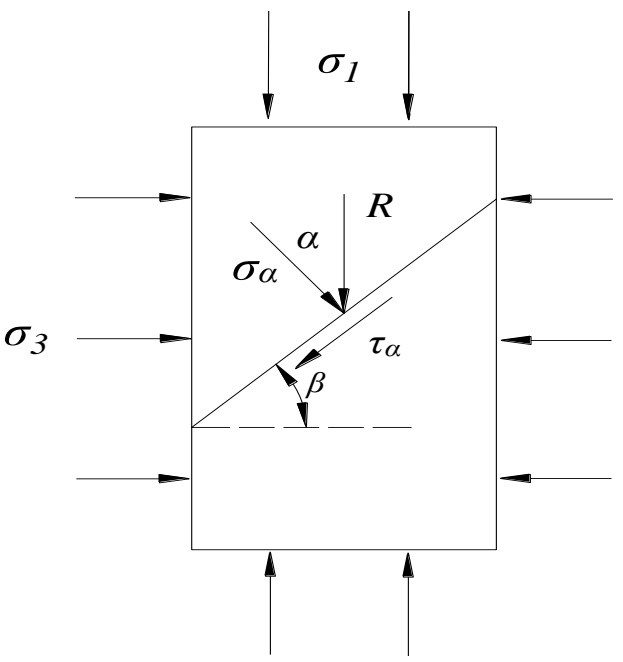

Fig.7 Frictional effect on structural surface

TABLE II. THE RATIO BETWEEN SHEAR AND NORMAL STRESS AT PEAK OF ABUTMENT PRESSURE IN FRONT OF COAL WALL UNDER DIFFERENT ADVANCING STEPS

\begin{tabular}{|c|c|c|c|c|c|c|c|c|c|}
\hline Distance from working face $/ \boldsymbol{m}$ & 80 & 60 & 40 & 25 & 4 & 0 & -4 & -16 & -36 \\
\hline Working face advancing steps/m & 16 & 36 & 56 & 71 & 92 & 96 & 100 & 112 & 136 \\
\hline Normal stress $\sigma_{\alpha} / \mathrm{MPa}$ & 30.76 & 32.35 & 36.98 & 49.25 & 50.43 & 22.03 & 74.38 & 48.27 & 47.68 \\
\hline Shear stress $\tau_{\alpha} / \mathrm{MPa}$ & 5.877 & 5.477 & 6.920 & 15.81 & 10.55 & 12.66 & 19.92 & 5.225 & 3.616 \\
\hline $\tan \alpha$ & 0.191 & 0.169 & 0.187 & 0.321 & 0.209 & 0.575 & 0.268 & 0.108 & 0.001 \\
\hline
\end{tabular}

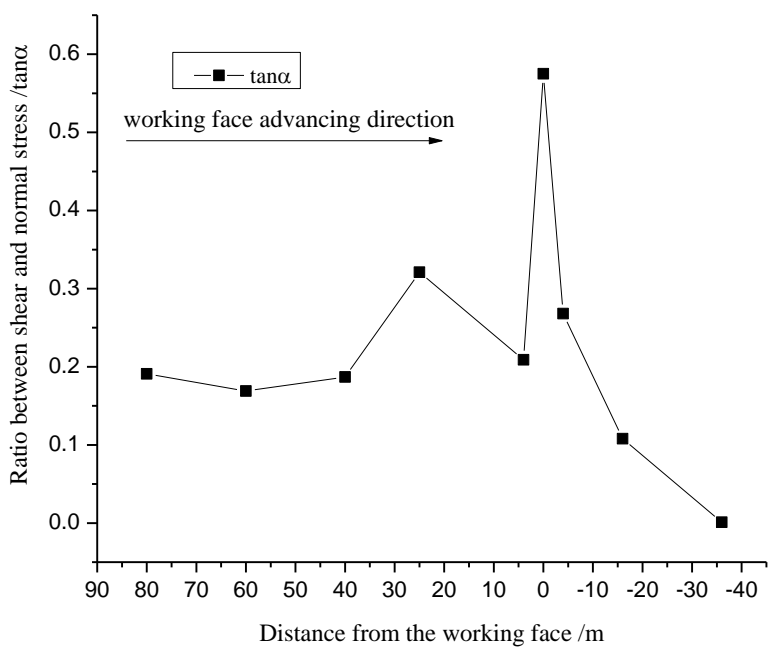

Fig.8 Curves of tan $\alpha$ position of abutment pressure peak under different distances from the synclinal axis

\section{b) Analysis of numerical test results}

Under the different advancing steps, value of tan $\alpha$ was listed in Table II at the position of abutment pressure peak in front of coal wall, and the corresponding $\tan \alpha$ curve was shown in Fig. 8, where the "-" said that the working face had pushed through the synclinal axis.

From Fig. 8: (1) when distance from working face to the syncline axis was $40 \mathrm{~m}$ outside, the value of $\tan \alpha$ at position of abutment pressure peak in the front of working face changed little, which focused around 0.18 . And high residual tectonic stress in the axis had little effect on risk of working face burst; (2) when distance was less than $40 \mathrm{~m}$, the value of $\tan \alpha$ rapidly grew. In the working face advancing to the synclinal axis, tan $\alpha$ reached the maximum value 0.575 . At this moment, probability of shearing instability occurring in front of the coal wall was larger, and the risk of burst was higher.(3) When the working face passed the synclinal axis, value of $\tan \alpha$ began to decrease, and risk of rock burst decreased. (4) High stress in the synclinal axis made the mechanical state of the structural plane of coal and rock mass at position of the abutment pressure peak in the front of working face changed. The closer to the synclinal axis, the higher value of shear stress, the bigger value of tanand the bigger risk of instability of coal wall burst.

\section{Energy analysis of risk of rock burst in front of coal wall}

\section{a) Energy criterion of starting risk of rock burst}

According to the least energy principle of dynamic failure of rock mass and energy theory, when the energy released by the mechanical balance state instability in the coal body and the surrounding rock system was greater than the energy consumed, rock burst was induced [21]. Then the energy criterion of starting risk of rock burst was established:

$$
\begin{aligned}
E_{0}-E_{c}= & \frac{\sigma_{1}^{2}+\sigma_{2}^{2}+\sigma_{3}^{2}-2 \mu\left(\sigma_{1} \sigma_{2}+\sigma_{1} \sigma_{3}+\sigma_{2} \sigma_{3}\right)}{2 \mathrm{E}} \\
& -\frac{\sigma_{c}^{2}}{2 E} \quad\left(\text { or }-\frac{\tau_{c}^{2}}{2 E}\right)
\end{aligned}
$$

Where $E_{0}$ was the elastic strain energy of coal body under the three to the stress state; $E_{c}$ was the energy consumed by the coal rock mass destruction; $\mathrm{E}$ was the elastic modulus; $\mu$ 
was the Poisson's ratio; and $\sigma_{1} 、 \sigma_{2}$ and $\sigma_{3}$ stood for the first、 second and third principle stress.

By (16) known: for a special coal seam, $E$ and $\mu$ were constant, therefore, the elastic strain energy that stored in the studied area depended on the size of principle stress in this area. When $E_{0}>E_{c}$, rock burst may be induced in front of coal wall; meanwhile, the greater the value was, the higher danger of rock burst would be.

TABLE III. STRESS STATE AT POSITION OF ABUTMENT PRESSURE PEAK

\begin{tabular}{|c|c|c|c|}
\hline $\begin{array}{c}\text { Face away from synclinal } \\
\text { axis } / \mathbf{m}\end{array}$ & $\begin{array}{c}\text { Maximum principal stress } \\
\boldsymbol{\sigma}_{\mathbf{1}} / \mathbf{M P a}\end{array}$ & $\begin{array}{c}\text { Intermediate principal stress } \\
\boldsymbol{\sigma}_{\mathbf{2}} / \mathbf{M P a}\end{array}$ & $\begin{array}{c}\text { Minimum principal stress } \\
\boldsymbol{\sigma}_{3} / \mathbf{M P a}\end{array}$ \\
\hline 60 & 33.400 & 11.000 & 8.779 \\
\hline 40 & 32.920 & 13.340 & 10.480 \\
\hline 25 & 52.150 & 25.560 & 20.810 \\
\hline 4 & 53.090 & 26.930 & 25.150 \\
\hline 0 & 56.930 & 25.680 & 16.510 \\
\hline-4 & 53.330 & 25.330 & 18.750 \\
\hline-16 & 48.780 & 16.50 & 14.470 \\
\hline-36 & 46.140 & 16.220 & 16.030 \\
\hline
\end{tabular}

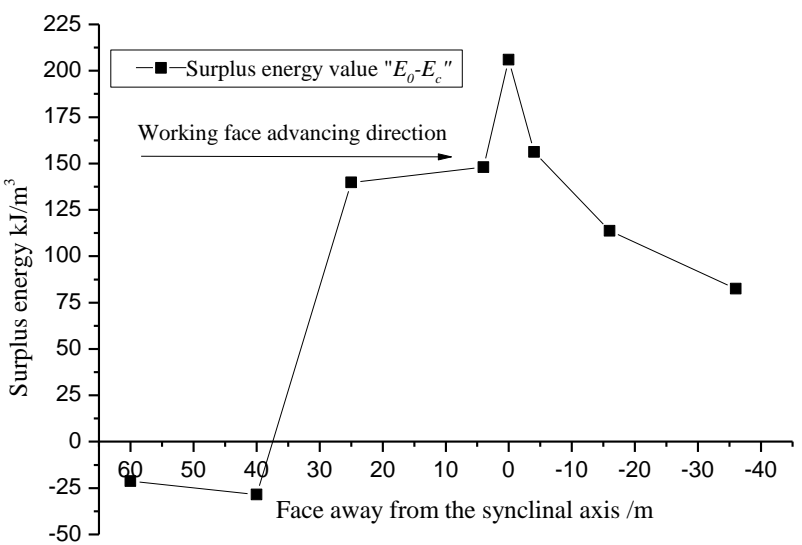

Fig.9 Curve of " $E_{0}-E_{c}$ " at peak of abutment pressure in different distances between synclinal axis and coal wall

\section{b) Result analysis}

The zones of abutment pressure increased in front of coal wall was a serious area of risk of rock burst, and the risk of rock burst at the position of abutment pressure peak was mainly studied by the numerical simulation. When coal compressive strength $\sigma c$ was $35.7 \mathrm{MPa}$, and elastic modulus $E$ was $4.43 \mathrm{GPa}, E_{c}$, the energy consumed by the coal destruction, was $143.85 \mathrm{~kJ} / \mathrm{m}^{3}$. With the different advancing distances, stress state at position of abutment pressure peak in front of coal wall was shown in table 3. The value of corresponding surplus energy " $E_{0}-E_{c}$ " was got by the (16) and the curve of " $E_{0}-E_{c}$ " was shown in Fig.9, in which the symbol "-" represented that working face had passed the synclinal axis.

From Fig. 9: (1) when distance from working face to the synclinal axis was more than $40 \mathrm{~m}$, the " $E_{0}-E_{c}$ " value was negative, and risk of rock burst was less; (2) when distance was less than $40 \mathrm{~m}$, with the working face advancing to the synclinal axis gradually, the " $E_{0}-E_{c}$ " value was grew, and the risk of rock burst was greater constantly; (3) when working face reaching to the synclinal axis, the " $E_{0}-E_{c}$ " value reached the maximum $205.93 \mathrm{~kJ} / \mathrm{m}^{3}$. And taking dynamic load effect into account, the risk of working face burst in the synclinal axis was greatly improved; (4) When working face passed the synclinal axis, the " $E_{0}-E_{c}$ " value decreased continuously, and the risk of rock burst began to weaken.

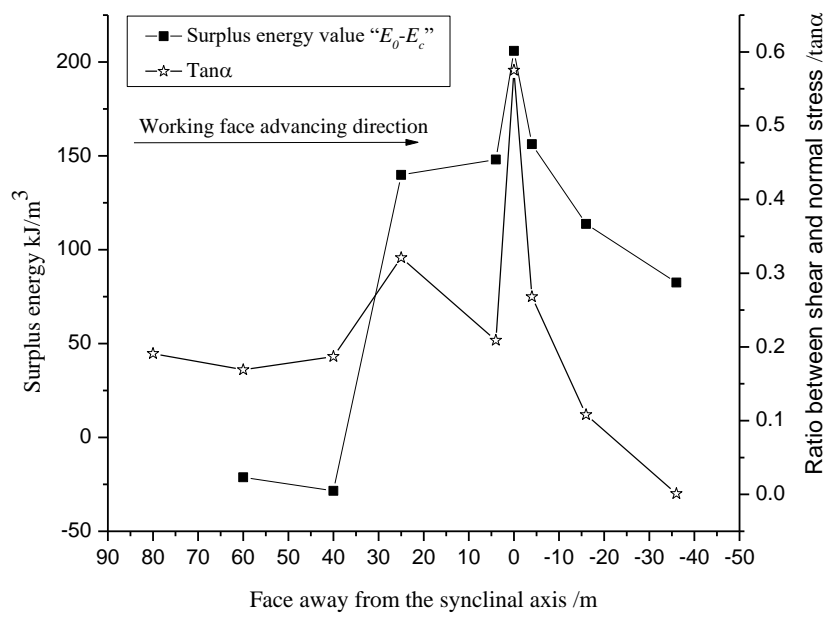

Fig.10 Contrast curve of “ $E_{0}-E_{c}$ ” and “ $\tan \alpha$ ” at peak of abutment pressure in different distance of working face to synclinal axis

\section{Comprehensive analysis of shear instability and impact energy of coal rock mass}

According to the solution formula of stress state in the plane state:

$$
\begin{gathered}
\sigma_{n}=\frac{\sigma_{1}+\sigma_{3}}{2}+\frac{\sigma_{1}-\sigma_{3}}{2} \cos 2 \alpha \\
\tau_{n}=\frac{\sigma_{1}-\sigma_{3}}{2} \sin 2 \alpha
\end{gathered}
$$

As well as (14), (15), it was known that whether coal and rock mass would occur shear instability or not was related to the maximum principal stress and the minimum principal stress which was related to surplus energy. So there was a certain relation between shear instability and the surplus energy in the coal and rock mass. "Tan $\alpha$ " curve and surplus 
energy " $E_{0}-E_{c} "$ curve were plotted in the same diagram at abutment pressure peak under different distances away from synclinal axis, shown in Fig. 10, where "-" where the "-" said that working face had pushed the synclinal axis.

From Fig. 10: (1) when distance from working face to the syncline axis was $40 \mathrm{~m}$ outside, the two curves changed slowly, and risk of burst was small; (2) when distance was less than $40 \mathrm{~m}$, "tan $\alpha$ " and " $E_{0}-E_{c}$ " values increased rapidly with risk of burst increasing, both of which reached the maximum in the axial part of the syncline; (3) When working face passed the synclinal axis, " $\tan \alpha$ " and " $E_{0}-E_{c}$ " values decreased and risk of rock burst weakened continuously. In the process of working face advancing to the synclinal axis, therefore, curves of "tan $\alpha$ " and surplus energy " $E_{0}-E_{c}$ " had a same variation trend.

\section{CONCLUSIONS}

(1) In the sectional flexural stiffness EI being certain, depth coal seam buried was deeper, average bulk density of overlying strata was larger, and the foundation coefficient was smaller, the syncline was formed easily. Strain energy was different in different positions of the syncline. When tectonic couple was larger and flexural stiffness was smaller, strain energy was greater in the micro segment $\mathrm{dx}$.

(2) The greater degree of syncline depression was, the greater synclinal tectonic stress was. In the mining engineering, syncline upper or lower sections with thick key strata, which withstood high tectonic stress, easily led to rock burst disaster due to improper mining.

(3) Affected by high tectonic stress in the synclinal axial part, the law of abutment pressure distribution in front of working face was shown: along with the advance of working face, abutment pressure in front of working face and high tectonic stress of the syncline had a "connection superimposed - Separation" relationship. The connecting and superimposed areas were serious areas where risk of burst occurred.

(4) With the working face advancing to synclinal axis gradually, value of surplus energy " $E_{0}-E_{c} "$ and $\tan \alpha$ of abutment pressure in front of coal wall were grew, then the risk of burst was greater constantly. When working face passed synclinal axis, both began to reduce, the risk of burst began to weaken gradually.

\section{ACKNOWLEDGMENT}

In this paper, this work is supported by the Shandong Provincial Natural Science Foundation, China (ZR2018MEE009), the State Key Research Development Program of China (2016YFC0801403-3), National Natural Science Foundation of China (51374140), and . State Key Laboratory of Mining Disaster Prevention and Control Cofounded by Shandong Province and the Ministry of Science and Technology (MDPC2016ZR04).

\section{REFERENCES}

[1] Sun Jin-shan, Zhu Qi-hu, and LU Wen-bo. Numerical simulation of rock burst in circular tunnels under unloading conditions. Journal of China University of Mining and Technology, 2007, 17(4):552-556.

[2] Gu S T, Xiao Z M, Huang R F, Li E, and Tan Y L. Danger mechanism of rock burst induced by mining in synclinal influence area. Electronic Journal of Geotechnical Engineering, 2015, 20(12):5103-5114.

[3] Qi Qingxin, and Dou linming. Theory and technology of rock burst. Xuzhou: China University of Mining and Technology Press, 2008.

[4] Dou Lin-ming, He Jiang, Cao An-ye, Gong Si-yuan, and Cai Wu. Rock burst prevention methods based on theory of dynamic and static combined load induced in coal mine. Journal of China Coal Society, 2015, 40(7):1469-1476. (In Chinese)

[5] Zhu Guang'an, Dou Linming, Liu Yang, Su Zhenguo, Li Hui, and Li Jing. Dynamic analysis and numerical simulation of fault slip instability induced by coal extraction. Journal of China University of Mining and Technology, 2016, 45(1):27-33.

[6] Li Z H, Dou L M, Lu C P, Mu Z L, and Cao A Y. Study on fault induced rock bursts. International Journal of Mining Science and Technology, 2008, 18:321-326.

[7] Sainoki A, and Mitri H S. Dynamic behaviour of mining-induced fault slip. International Journal of Rock Mechanics and Mining Sciences, 2014, 66(1):19-29.

[8] Sainoki A, and Mitri H S. Dynamic Modelling of Fault Slip Induced by Stress Waves due to Stope Production Blasts. Rock Mechanics and Rock Engineering, 2016, 49(1):165-181.

[9] Li Zhenlei, Dou Linming, Cai Wu, He Jiang, Wang Guifeng, Liu Jun, and Han Rongjun. Fault pillar induced rock burst mechanism of thick coal seam in deep mining. Chinese Journal of Rock Mechanics and Engineering, 2013, 32(2):333-342.

[10] Cai Wu. Study on the principle of superposition of static and dynamic load and its monitoring and early warning of rock burst of fault. Xuzhou: China University of Mining and Technology press, 2008.

[11] Liu X S, Tan J, Tan Y L, and Hu S C. Pattern Recognition of Signals for the Fault-Slip Type of Rock Burst in Coal Mines. Shock and Vibration,2015,(2015-9-7), 2015, 2015(6):1-8.

[12] Guo W Y, Zhao T B, Tan Y L, Yu F H, Hu S C, and Yang F Q. Progressive mitigation method of rock bursts under complicated geological conditions. International Journal of Rock Mechanics and Mining Sciences, 2017, 96:11-22.

[13] Zhang C Q, Feng X T, Zhou H, Qiu S L, and Wu W P. Case Histories of Four Extremely Intense Rockbursts in Deep Tunnels. Rock Mechanics and Rock Engineering, 2012, 45(3):275-288.

[14] Wang Y G. Research on rock burst rules and prevention near fold. China Mining University, 2008.

[15] Jiang Fuxing, Miao Xiaohu, Wang Cunwen, Song Jiahong, Deng Jianming, and Meng Fei. Predicting research and practice of tectoniccontrolled coal burst by micro seismic monitoring. Journal of China Coal Society, 2010, 35(6):900-903.

[16] Gu S T, Huang R F, Tan Y L, Li W S, and Xiao Z M. Formation mechanism of anticline structure and its disastrous mechanism of rock burst. Journal of Mining and Safety Engineering, 2015, 32(1):59-64.

[17] He H, Dou L M, Gong S Y, Zhou P, Xue Z J, and Jiang H. Study of mining shock in high tectonic stress zones. Journal of China University of Mining and Technology, 2011, 40(1): 7-13.

[18] Jiang Yaodong, Pan Yishan, Jiang Fuxing, Dou Linming, and Ju Yang. State of the art review on mechanism and prevention of coal bumps. Journal of China Coal Society, 2014, 39(2):205-213.

[19] Huang Yi, and He Fangshe. Elastic foundation beam, plate, shell. Beijing: Science Press, 2005.

[20] Yang Xuexiang. The feature of foundation pressure on Winkler Foundation-Beam with one fixed and its application. Engineering Mechanics, 2006, 23 (11):76-79.

[21] Zhao Yangsheng, Feng Zengchao, and Wan Zhijun. Least energy principle of dynamical failure of rock mass. Chinese Journal of Rock Mechanics and Engineering, 2003, 22(11):1781-1783. 